\title{
Drug-induced liver injury
}

\author{
Alexander Kumachev MD MSc, Peter E. Wu MD MSc
}

Cite as: CMAJ 2021 March 1;193:E310. doi: 10.1503/cmaj.202026

1

Drug-induced liver injury can be caused by a variety of medications, supplements and herbal products (Appendix 1, available at www.cmaj.ca/lookup/doi/10.1503/cmaj.202026/ tab-related-content)

Drug-induced liver injury is estimated to have an incidence of 14-19 cases per 100000 individuals. ${ }^{1,2}$ Although asymptomatic liver enzyme elevation is the most common presentation, drug-induced liver injury is the most common cause of acute liver failure in most Western countries, accounting for more than $50 \%$ of cases. ${ }^{1}$ Drug-induced liver injury can occur in overdose or at therapeutic dosing, either because of direct, intrinsic drug hepatotoxicity or as a result of idiosyncratic (unpredictable) hepatotoxicity.

2

Drug-induced liver injury should be suspected in patients with new elevation of liver enzymes, prompting a review of drug exposures dating back as far as 3 months

Establishing a reliable timeline between exposure and injury onset is critical. Typical latency periods are 1-5 days with direct, and 5-90 days with idiosyncratic hepatotoxicity. ${ }^{1}$ Idiosyncratic hepatotoxicity can occur sooner if there has been previous exposure. ${ }^{2}$ Patterns of enzyme elevation include hepatocellular, cholestatic or mixed; attributing elevation patterns to specific drugs can be imprecise. LiverTox is a website sponsored by the National Institutes of Health, with descriptions of more than 1000 agents that can cause drug-induced liver injury. ${ }^{3}$

\section{Diagnosis requires exclusion of alternate causes}

Drug-induced liver injury can be particularly difficult to distinguish from autoimmune hepatitis because antibodies seen in this kind of hepatitis may also be positive in drug-induced liver injury. ${ }^{2}$ The Roussel Uclaf Causality Assessment Method (RUCAM) score is a clinical decision tool to help determine the probability of drug-induced liver injury. ${ }^{2}$ after drug discontinuation

Liver enzyme levels usually decrease within days to weeks, with less than $10 \%$ of patients having chronic disease 1 year later. ${ }^{2,4}$ In cases of severe elevation of liver enzyme levels (alanine aminotransferase $\geq 5 \times$ or alkaline phosphatase $\geq 2 \times$ and total bilirubin $\geq 2 \times$ upper limit of normal), ${ }^{2}$ clinical signs of liver failure, or if improvement is not seen within the expected time frame, specialist consultation and investigations (e.g., liver biopsy) for alternative causes or complications of drug-induced liver injury should be pursued. ${ }^{2}$

\section{Treatment requires identification and discontinuation of the culprit drug} Targeted therapy is appropriate for specific cases (e.g., $\mathrm{N}$-acetylcysteine for acetaminophen toxicity ${ }^{5}$ ), but treatment is primarily to stop the offending drug. Glucocorticoids are not routinely recommended, although they may have a role in patients with features of hypersensitivity reactions and multiorgan involvement, or if autoimmune hepatitis is an ongoing concern. ${ }^{2}$ Liver transplantation should be considered in severe cases.

\section{References}

1. Hoofnagle JH, Björnsson ES. Drug-induced liver injury types and phenotypes. N Engl J Med 2019;381:264-73.

2. European Association for the Study of the Liver. EASL clinical practice guidelines: drug-induced liver injury. J Hepatol 2019;70:1222-61.

3. LiverTox: Clinical and research information on drug-induced liver injury [Internet]. Bethesda (MD): National Institute of Diabetes and Digestive and Kidney Diseases; 2012 (updated 2020 July 1). Available: www.ncbi.nlm.nih.gov/books/NBK548196/ (accessed 2020 Aug. 12).

4. David S, Hamilton JP. Drug-induced liver injury. US Gastroenterol Hepatol Rev 2010;6:73-80.

5. Polson J, Lee WM. AASLD position paper: the management of acute liver failure. Hepatology 2005;41:1179-97.

\section{Competing interests: None declared.}

This article has been peer reviewed.

Affiliations: Department of Medicine (Kumachev, Wu) and Divisions of Clinical Pharmacology and Toxicology (Kumachev, Wu) and General Internal Medicine (Wu), University of Toronto, Toronto, Ont.

Content licence: This is an Open Access article distributed in accordance with the terms of the Creative Commons Attribution (CC BY-NC-ND 4.0) licence, which permits use, distribution and reproduction in any medium, provided that the original publication is properly cited, the use is noncommercial (i.e., research or educational use), and no modifications or adaptations are made. See: https://creativecommons.org/ licenses/by-nc-nd/4.0/

Correspondence to: PeterWu,Peter.Wu@uhn.ca 